\title{
Treatment with Natalizumab in Relapsing-Remitting Multiple Sclerosis Patients Induces Changes in Inflammatory Mechanism
}

\author{
Jaime Ramos-Cejudo • Celia Oreja-Guevara • \\ Luiz Stark Aroeira • Luis Rodriguez de Antonio • \\ Beatriz Chamorro • Exuperio Diez-Tejedor
}

Received: 18 January 2011 / Accepted: 25 March 2011 / Published online: 14 April 2011

(C) The Author(s) 2011. This article is published with open access at Springerlink.com

\begin{abstract}
Natalizumab is a widely accepted drug for the relapsing-remitting subtype of multiple sclerosis (RRMS). The present longitudinal exploratory study in RRMS patients analyzes the effects of natalizumab treatment on the levels of pro-inflammatory and anti-inflammatory cytokine protein levels and also the frequency and suppressor function of regulatory $\mathrm{T}$ cells. Flow cytometry was used to determine cytokines and regulatory $\mathrm{T}$ cell frequency while regulatory $\mathrm{T}$ cell suppressor function was assayed in vitro at different time-points after starting with natalizumab. Results showed serum levels of proinflammatory interferon gamma and interleukin (IL)12 p70, as well as anti-inflammatory IL-4 and IL-10, were
\end{abstract}

C. Oreja-Guevara $\cdot$ L. Rodriguez de Antonio - B. Chamorro •

E. Diez-Tejedor

Department of Neurology, Health Research Institute (IdiPAZ),

University Hospital La Paz/Autónoma University of Madrid,

Madrid, Spain

C. Oreja-Guevara $\cdot$ L. Rodriguez de Antonio - B. Chamorro

E. Diez-Tejedor

Neuroimmunology and Multiple Sclerosis Unit,

Health Research Institute (IdiPAZ),

University Hospital La Paz/Autónoma University of Madrid,

Madrid, Spain

J. Ramos-Cejudo $\cdot$ L. Stark Aroeira $\cdot$ E. Diez-Tejedor

Neuroscience Research Laboratory,

Health Research Institute (IdiPAZ),

University Hospital La Paz/Autónoma University of Madrid,

Madrid, Spain

C. Oreja-Guevara $(\bowtie)$

Department of Neurology, University Hospital La Paz,

Paseo de la Castellana, 261,

28046 Madrid, Spain

e-mail: unidadem.lapaz@gmail.com elevated just a few hours or days after first IV infusion of natalizumab. Interestingly, other cytokines like IL-5 or IL13 were also elevated while pro-inflammatory IL-17, IL-2, and IL-1 $\beta$ increased only after a long-term treatment, suggesting different immune mechanisms. In contrast, we did not observe any effect of natalizumab treatment on regulatory $\mathrm{T}$ cell frequency or activity. In conclusion, these results suggest natalizumab has other immunological effects beyond VLA-4 interaction and inhibition of CNS extravasation, the relevance of which is as yet unknown and warrants further investigation.

Keywords Multiple sclerosis (MS) - natalizumab · cytokines $\cdot$ peripheral blood $\cdot$ regulatory T cells $\cdot$ TH1

\section{Introduction}

Multiple sclerosis (MS) is a chronic autoimmune disease of the central nervous system (CNS) in which the cytokines and the inflammatory process are key factors. Cytokines like interleukin (IL)-4, IL-2, or interferon gamma (IFN- $\gamma$ ) have been widely studied in MS because of their immunomodulatory role. A critical step in the inflammatory process underlying MS pathology is immune cell trafficking across the blood-brain barrier, and this is associated with worsening clinical symptoms. Natalizumab (Tysabri ${ }^{\circledR}$, Biogen Idec, CA), a monoclonal antibody designed against the $\alpha 4$ subunit of $\alpha 4 \beta 1$ (very late antigen-4; VLA-4) and $\alpha 4 \beta 7$ receptors located on the lymphocyte surface, has demonstrated efficacy in reducing disease activity and relapse frequency in MS patients and is widely accepted as a drug for the relapsing-remitting subtype of multiple sclerosis (RRMS)[13]. The humanized IgG4 specifically binds to the surface of 
mononuclear circulating blood cells presenting $\alpha 4$, thus inhibiting the adhesion to the VCAM at the endothelium and decreasing extravasation to adjacent tissues. In the context of MS, which is usually considered a $\mathrm{T}$ cell autoimmune disease affecting the CNS, the beneficial effects observed with the treatment have been attributed to immunosuppression by a blockade on $\mathrm{T}$ cell trafficking through the endothelium $[4,5]$.

The clinical improvement and efficacy observed in natalizumab treatment are counter-weighted by important side effects including opportunistic infections and also cases of fatal progressive multifocal leukoencephalopathy (PML) detected during the clinical trials [1]. Some questions still remain unresolved as the effect of natalizumab in the first days and months of treatment when allergic reactions and acute infusion reactions can occur [6]. Antibody binding to the VLA-4 receptor may not only play a role in inhibiting the inflammation process but also have effects on the immune system itself.

Although the mechanism of action of the drug is supposed to be clear, the biological effects of integrin $\alpha 4$ blockade or $\mathrm{T}$ cell traffic inhibition are still unknown. Already existing drugs for MS like interferon-beta or glatiramer acetate seem to modify $\mathrm{CD} 4^{+} \mathrm{CD} 25^{+}$Foxp3 regulatory $\mathrm{T}$ cell activity [7-10] or promote the antiinflammatory cytokine pathway [11-14]. The goal of our study was to gain insight into the immunological effects of natalizumab treatment in RRMS patients over a period of 20 months with a focus on pro-inflammatory and antiinflammatory cytokine protein levels as well as regulatory $\mathrm{T}$ cell frequency and suppressor function.

\section{Patients and Methods}

\section{Patients}

Twenty-two RRMS patients were recruited and followed in an observational longitudinal cohort study over a period of 20 months after starting treatment with natalizumab (standard - 300 mg IV every 4 weeks). All patients fulfilled the McDonald criteria for relapsing-remitting multiple sclerosis [15]. Clinical follow-up consisted of neurological visits with a rating on the expanded disability status scale (EDSS) every 6 months. Blood samples were taken at $2 \mathrm{~h}$; 4, 7, and 15 days; and 1 and 2 months, and one sample from the 3-5-, 9-12-, and 15-20-month periods, always before drug infusion; all samples were processed within $2 \mathrm{~h}$ of extraction. All patients had been treated with immunomodulatory treatments (glatiramer acetate or $\beta$-interferon) before starting with natalizumab (minimum wash-out period of 1 month except 15 days for one patient). Patients treated with immunosuppressive drugs or with cortico- steroids for relapses less than 30 days before starting with natalizumab were not included in this study. Control blood samples were obtained from healthy donors recruited in our facilities (six women and five men; age range, 25-30 years old). The study was approved by the ethics committee of our hospital, and all patients and controls included signed an informed consent.

The mean age of RRMS patients was $35.53 \pm 8$ years, and women comprised the $75 \%$ (Table I). The median EDSS at the beginning of the study was 3.69 and 3.73 after 1 year. The annual relapse rate (ARR) was 2.5, and the disease duration was $9.95 \pm 6$ years. None of the patients received immunomodulatory or immunosuppressive drug treatment during the experiment, and one patient interrupted treatment due to allergic side effects within the first 2 months. Clinical laboratory parameters showed increased levels in the total lymphocytes after 1 year. We obtained significantly higher levels of IL-2, IL-8, and IFN- $\gamma$ when comparing RRMS patients at baseline with healthy controls (Table II), which agrees with previous MS reports.

Clinical disease activity was evaluated with the EDSS scale. Patients were classified in subgroups according to EDSS values (0-3.5, 4-6.5) and the evidence of relapses within the first year (yes or none). Laboratory parameters were measured including LDH, transaminases, total lymphocytes, eosinophils and monocytes, and the total CD4 and $\mathrm{CD} 8$ counts.

Table I Patients' characteristics at baseline and after treatment

\begin{tabular}{ll}
\hline Clinical laboratory data & RRMS $(n=22)$ \\
\hline Mean age (years) & $35.53 \pm 8$ \\
Sex (men/women) & $5 / 17$ \\
Men disease duration (years) & $9.95 \pm 6$ \\
EDSS (number of subjects) & \\
$0-3.5$ & 8 \\
$4-6.5$ & 14 \\
Mean EDSS (initial/after 1 year) & $3.69 / 3.73$ \\
Treatments in the last 60 days & \\
Glatiramer acetate & 8 \\
Interferon- $\beta$ & 14 \\
Corticosteroids/others & 0 \\
Naïve patients & 0 \\
Mean number of relapses & \\
Previous year & 1.73 \\
First year with natalizumab & 0.29 \\
\% of relapse reduction & $83.1 \%$ \\
Median cell count $[$ baseline $/ 1$ st Year $/ 2$ nd year $]$ & \\
Total lymphocytes $\left(\times 10^{3} / \mu \mathrm{L}\right)$ & $1.91 / 2.64 / 3.43$ \\
Total monocytes $\left(\times 10^{3} / \mu \mathrm{L}\right)$ & $0.51 / 0.49 / 0.52$ \\
CD4 $(\%)$ & $39.0 \% / 41.0 \% / 41.0 \%$ \\
CD8 (\%) & $33.0 \% / 26.0 \% / 25.0 \%$ \\
\hline
\end{tabular}


Table II Levels of cytokines in RRMS patients (baseline) compared to controls

\begin{tabular}{lccllr}
\hline Cytokines & RRMS & Controls & Cytokines & RRMS & \multicolumn{1}{c}{ Controls } \\
\hline IL-1 $\alpha$ & $4.53( \pm 2.23)$ & $5.03( \pm 3.67)$ & IL-12p70 & $4.11( \pm 1.25)$ & $3.25( \pm 1.68)$ \\
IL-1 $\beta$ & $2.44( \pm 0.5)$ & $1.98( \pm 1.22)$ & IL-13 & $2.75( \pm 1.05)$ & $2.5( \pm 1.21)$ \\
IL-2 & $15.53( \pm 4.83)^{*}$ & $12.30( \pm 1.23)^{*}$ & IL-17 & $4.41( \pm 1.76)$ & $4.22( \pm 1.35)$ \\
IL-4 & $3.50( \pm 1.28)$ & $3.06( \pm 2.02)$ & IFN- $\gamma$ & $4.58( \pm 2.3)^{*}$ & $2.51( \pm 1)^{*}$ \\
IL-5 & $1.99( \pm 0.6)$ & $2.2( \pm 0.9)$ & TNF- $\alpha$ & $6.55( \pm 2.56)$ & $5.80( \pm 1.53)$ \\
IL-6 & $4.01( \pm 2.25)$ & $5.86( \pm 3.02)$ & GM-CSF & $2.72( \pm 1.25)$ & $4.5( \pm 3.10)$ \\
IL-8 & $26.31( \pm 11.56)^{*}$ & $11.54( \pm 4.12)^{*}$ & MCP-1 & $98.28( \pm 49.25)$ & $74.25( \pm 39.25)$ \\
IL-10 & $3.26( \pm 1.4)$ & $3.36( \pm 1.30)$ & & & \\
\hline
\end{tabular}

\section{Cytokine Determination}

All serum samples for cytokine determination were obtained from $8 \mathrm{~mL}$ of fresh blood, centrifuged and stored in $1.5 \mathrm{~mL}$ tubes, and frozen at $-80^{\circ} \mathrm{C}$ until measured by flow cytometry (CBA FlexSet-BD ${ }^{\mathbb{E}}$ Bioscience, Bedford, MA, USA) following manufacturer's instructions. Experiments were carried out using a FACSCalibur Flow Cytometer (BD Bioscience, USA). Cytokines analyzed included in our analysis panel were (lower detection limits are shown): IL-1 $\alpha(1.0 \mathrm{pg} / \mathrm{mL}), \mathrm{IL}-1 \beta(2.3 \mathrm{pg} / \mathrm{mL}), \mathrm{IL}-2$ (11.2 pg/mL), IL-4 (1.4 pg/mL), IL-5 (1.1 pg/mL), IL-6 $(1.6 \mathrm{pg} / \mathrm{mL}), \mathrm{IL}-8(1.2 \mathrm{pg} / \mathrm{mL}), \mathrm{IL}-10(0.13 \mathrm{pg} / \mathrm{mL})$, IL$12 \mathrm{p} 70(0.6 \mathrm{pg} / \mathrm{mL}), \mathrm{IL}-13(0.6 \mathrm{pg} / \mathrm{mL}), \mathrm{IL}-17 \mathrm{~A}(0.3 \mathrm{pg} / \mathrm{mL})$, MCP-1 $(1.3 \mathrm{pg} / \mathrm{mL})$, GM-CSF $(0.2 \mathrm{pg} / \mathrm{mL})$, tumor necrosis factor (TNF; $0.7 \mathrm{pg} / \mathrm{mL})$, and INF- $\gamma(1.8 \mathrm{pg} / \mathrm{mL})$. All concentrations were transformed according to NIBSC/WHO standards.

\section{Regulatory T Cell Frequency and Activity}

PBMCs were isolated from $18 \mathrm{~mL}$ of fresh blood samples (stored in EDTA tubes) through Ficoll-Paque (GE-Healthcare, Amersham) density gradient centrifugation. Samples were processed within $2 \mathrm{~h}$ of collection to avoid any alterations. Regulatory $\mathrm{T}$ cells were isolated using a commercial regulatory $\mathrm{T}$ cell isolation kit (Miltenyi Biotec, Bergisch Gladbach, Germany) following the manufacturer's instructions. In order to analyze suppressor function, cells were stimulated with anti-CD3 plus anti-CD28 $(1 \mu \mathrm{g} / \mathrm{mL})$ in the presence or absence of previously purified regulatory $\mathrm{T}$ cells as previously described $[16] ; 1 \times 10^{5}$ of $\mathrm{T}$ $\mathrm{CD} 4^{+} \mathrm{CD} 25^{\text {high }}$ cells (activated regulatory $\mathrm{T}$ cells) were co-cultured (or not) with $2 \times 10^{5} \mathrm{~T}-\mathrm{CD} 4^{+} \mathrm{CD} 25^{\text {low }}$ cells (effector T cells). Purified T-CD $4^{+} \mathrm{CD} 25^{\text {low }}$ cells cultured alone were used as controls. After 7 days, cells were pulsed during the last $6 \mathrm{~h}$ of culture with $1 \mu \mathrm{Ci}\left[{ }^{3} \mathrm{H}\right]$-thymidine (PerkinElmer, Waltham, MA) and incorporation was measured in glass fiber filters (Filtermat A, Wallac, Oy Turku, Finland) using a 1450 Microbeta luminescence counter (PerkinElmer, Waltham, MA). Regulatory $\mathrm{T}$ cell markers were determined by flow cytometry (FACSCalibur). We used anti-CD4 and anti-CD25 (BD Bioscience) and also the anti-FoxP3 staining kit (BD Bioscience) according to the manufacturer's instructions. Cells were stained with antiCTLA-4, anti-HLA-DR and anti-CD38 in order to measure activation of regulatory $\mathrm{T}$ cell markers. Activated $\mathrm{T}$ cells were defined as CD4 + CD38+ HLA-DR $+\mathrm{T}$ cells as previously described by the group of Sánchez-Ramón [16].

\section{Stimulation and Proliferation Assay}

A total of $10^{5}$ isolated PBMCs purified from healthy control samples were cultured in medium $\left(\mathrm{GIBCO}^{\circledR} \mathrm{RPMI}\right.$ Media 1640-Invitrogen, CA, USA) in the presence of growing concentrations of natalizumab $(15,25$, and $125 \mu \mathrm{g} / \mathrm{mL}$ ). Cytokine levels were determined in supernatants obtained after 4 and $24 \mathrm{~h}$ using flow cytometry. Cells were pulsed with $1 \mu \mathrm{Ci}\left[{ }^{3} \mathrm{H}\right]$-thymidine for $16 \mathrm{~h}$ in order to determine proliferation levels.

\section{Statistical Analysis}

Due to asymmetrical distribution of the serum cytokine levels, summary statistics are given as median and interquartile range. After performing a non-parametric Friedman test in order to analyze significant differences, baseline cytokine levels were compared with levels at each different time-point using the Wilcoxon signed rank test. Patients were grouped depending on their EDSS (0-4, 4.56.5 ) and evidence of relapses (yes or none) during treatment. The same test was also used to compare the levels of regulatory $\mathrm{T}$ cell markers as well as the suppressor activity at the different time-points. In order to analyze associations between the number of relapses and the levels of specific cytokines, ranges were calculated for cytokine values by comparing levels (in each patient) at baseline and after 1 year. This allowed comparisons with the number of relapses. Correlations were established by Spearman's test. Also, we tried to correlate result data with the number of observed MRI lesions or the evidence (yes or none) of adverse drug reactions. A simple Mann-Whitney $U$ test 
was used to compare cytokine levels between RRMS patients at baseline with those in healthy donors. $P<0.05$ was considered as a significance threshold. Given the exploratory nature of this study, no corrections for multiple comparisons were made. Statistical analyses were performed using GraphPad Prism 5.0 (San Diego, CA, USA).

\section{Results}

Cytokine Levels in Patients After Starting Treatment

Globally, patients treated with natalizumab presented higher levels of both pro-inflammatory and anti-inflammatory cytokines on follow-up. Anti-inflammatory interleukins IL4, IL-5, IL-10, and IL-13 were significantly augmented just a few hours or days after the first administration (Fig. 1). In counterpart, pro-inflammatory IFN- $\gamma$ and IL-12p70 were also significantly increased and remained elevated during the first 2 months. Other cytokines included in our study tended to rise (i.e., the IL-6 or IL-17), but no increase reached significance. By the end of the first 2 months, all the cytokines had returned to baseline (non-significant) levels.

\section{Cytokine Levels in Long-Term Treatment}

In long-term measurements, levels of specific cytokines were also increased, but the overall response was more dissimilar. Interestingly, while cytokines elevated in the initial stage returned to basal levels, pro-inflammatory IL-17, IL-1 $\beta$, and IL-2 levels were increased (Fig. 2). Elevated levels were also obtained for the anti-inflammatory cytokines IL-5 and IL-13 after 1 year of treatment.

Overall, we observed that cytokines were elevated at different time-points and that they followed three different patterns (Fig. 3). Some of the cytokines (group A) were elevated only during the first month, just a few hours and days after drug infusion. These included both pro-inflammatory and anti-inflammatory cytokines (i.e., IL-4, IL-10, or IFN- $\gamma$ ). In contrast, the typically pro-inflammatory cytokines IL- $1 \beta$, IL-2, and IL-17 (group B) were elevated only at the long-term treatment. The last group, composed of anti-inflammatory cytokines (IL-5 and IL-13), was elevated at both time-points (group C), the beginning and at 1 year but not at the mid-term. The levels of IL- $1 \alpha$, IL- 6 , IL- 8 , TNF- $\alpha$, GM-CSF, and MCP1 seemed to be sustained at similar concentrations during treatment and were not significantly elevated at any time-point included in the study (data not shown).

\section{Regulatory T Cell Frequency and Activity in Patients}

Overall, the effect of natalizumab treatment on regulatory $\mathrm{T}$ cells was not statistically significant. We did not find differences in regulatory $\mathrm{T}$ cell frequency, although there was a very slight decrease during the first month (Fig. 4a). Levels of CD4 $+\mathrm{CD} 25^{\text {high }}$ Foxp3 + cells initially increased but, after 4 days, were back to baseline levels. Looking at the regulatory $\mathrm{T}$ cell activity, we also did not observe differences compared to baseline suppressor function of cells previously stimulated with anti-CD3 and anti-CD28 (Fig. 4b). In addition, there was no difference in CTLA4, CD38, and HLA-DR activation marker levels in the $\mathrm{CD} 4^{+}$ population.

\section{Natalizumab Effects on PBMCS In Vitro}

In vitro exposure to natalizumab does not affect proliferation or cytokine levels. Previous groups addressed this question in CD4+ T cells alone [17]. However, the VLA-4 antigen is present in many blood cell subtypes, so we cocultured purified PBMCs in the presence of natalizumab. We did not obtain significantly increased levels of proliferation in cells cultured in the presence of the antibody. Also, we did not obtain significantly different levels of cytokines when natalizumab was present (data not shown) in either 4- or 24-h cultures.

\section{Discussion}

This is the first study to show the effects of natalizumab over a period of 20 months with a special focus on the first hours, days, and months after initiating treatment. At the protein level, we have detected that natalizumab therapy is associated with an increase of pro-inflammatory and antiinflammatory cytokines within the first 2 months of treatment. This affects IFN- $\gamma$ and IL-12p70 and also the anti-inflammatory IL-4 or IL-10. Interestingly, important cytokines for MS such as IL-2, IL-17, or IL-1 $\beta$ were only elevated after 1 year of treatment, suggesting different immunologic mechanisms. It would be interesting to further analyze whether the reduction to basal levels in the cytokines after the first 2 months of treatment observed in our study might be associated with the recently described reduction in CD49d antigen expression and therefore a possible reduction of antibody binding in circulating cells [18]. A recent work has reported increased levels of T cells secreting pro-inflammatory cytokines in blood circulation in patients after 1 year of natalizumab treatment [17]. In agreement with these results, we observed elevated serum levels of pro-inflammatory IL-2, IL-17, and IL-1 $\beta$ after 1 year.

In our study of cytokines based on serum samples, we have also taken into account the first hours and days after the first administration of the antibody, when we were able to detect differences in cytokine levels such as IFN- $\gamma$, IL-4, 
IFN-g

IL-12p70

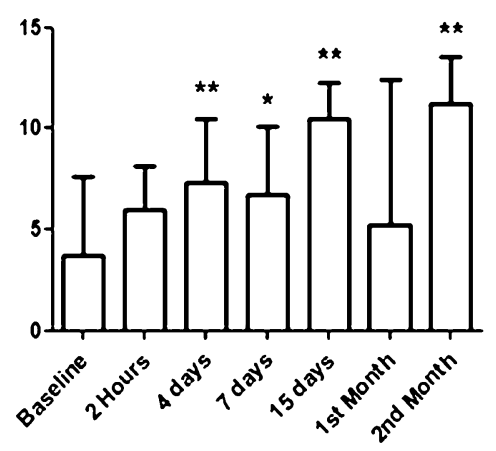

IL-2

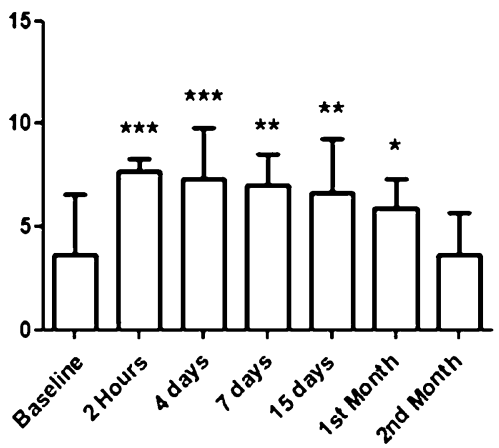

IL-1b

IL-17
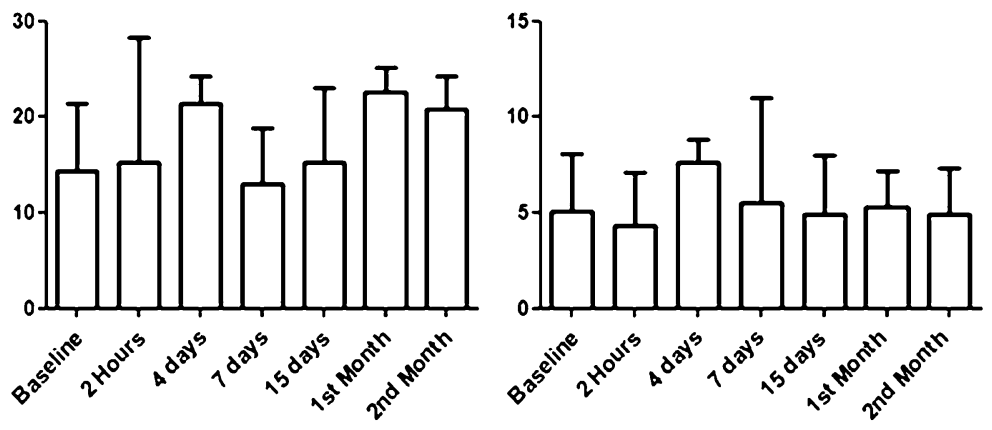

IL-4

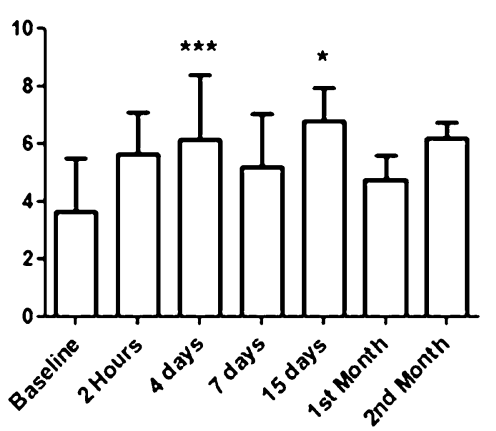

IL-10

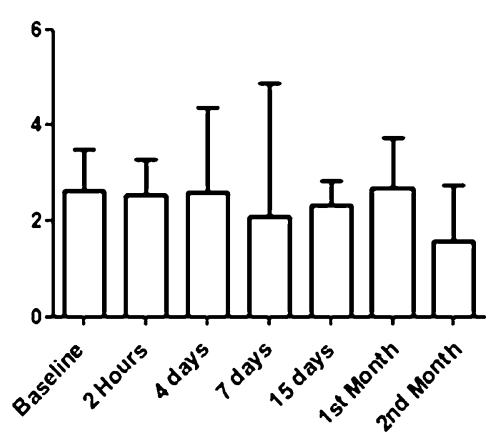

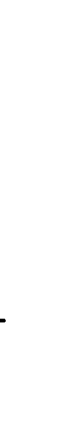

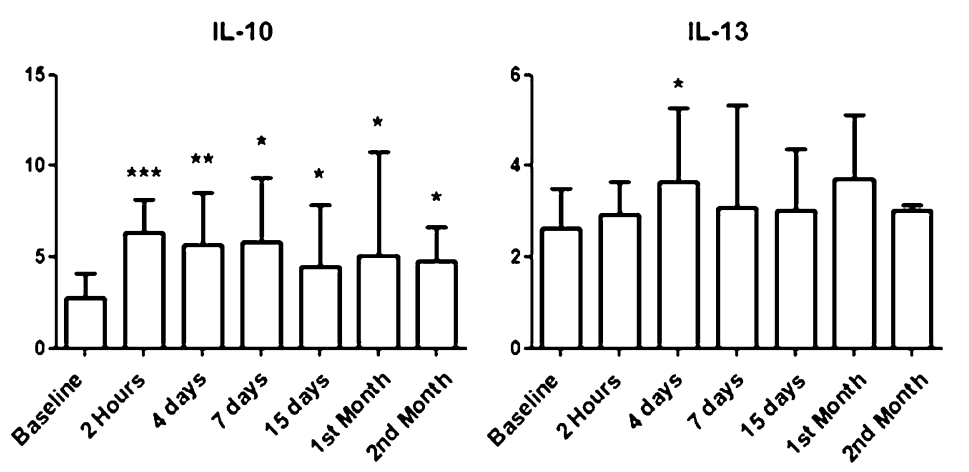

IL -5

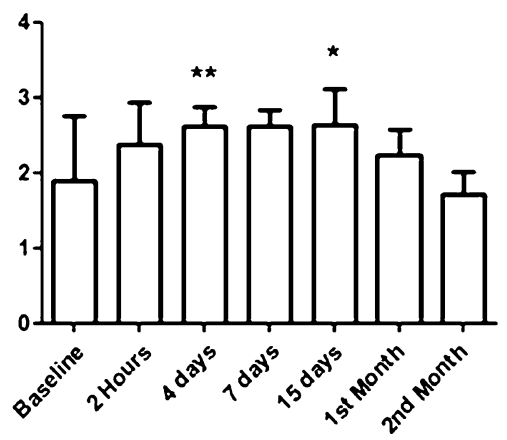

Fig. 1 Serum levels of cytokines in RRMS patients after starting treatment with Natalizumab. Increased levels were detected just few hours or days after first dosing with IFN- $\gamma$, IL-12p70 as well as IL-4, IL-5, IL-10, and IL-

or IL-10. A recent paper studying cytokines in patients with MS at baseline and after 1 year did not address some of the cytokines included in our study such us IL-17, IL-12p70, or
13, and remained elevated at different stages. By the end of the second month, all the cytokine levels returned to basal levels. Concentrations are given in picograms per milliliter. ${ }^{*} p<0.05,{ }^{* *} p<0.01,{ }^{* * *} p<0.001$

IL-13 [19]. Our study has detected increased levels for IL$1 \beta$, IL-2, and also IL17 in the long-term treatment. It would be interesting to analyze in the future if the IL-23, 


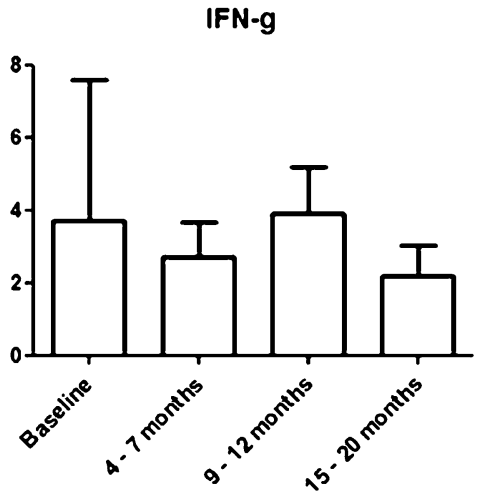

IL-2

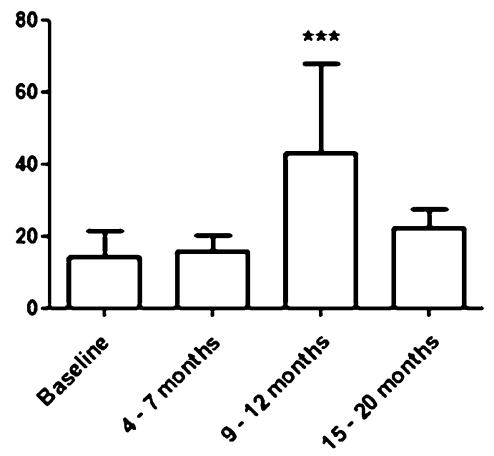

IL-4

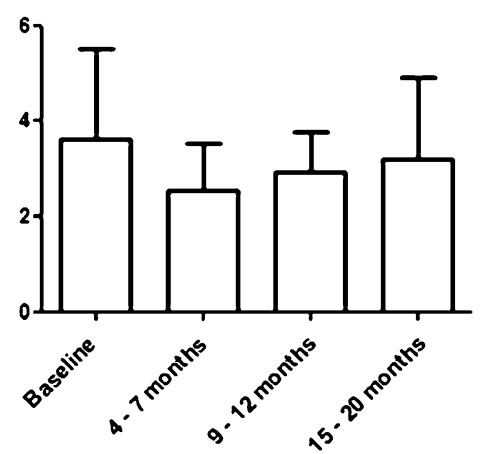

IL.5

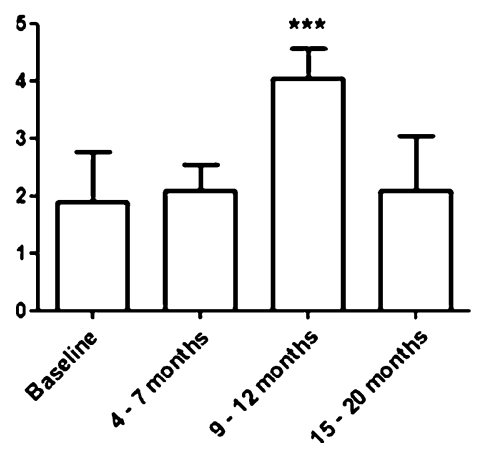

IL-12p70

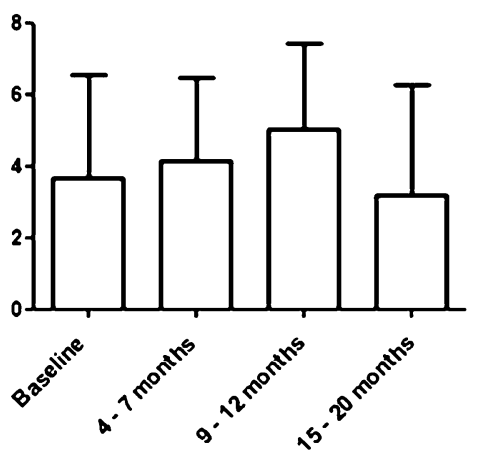

IL-17

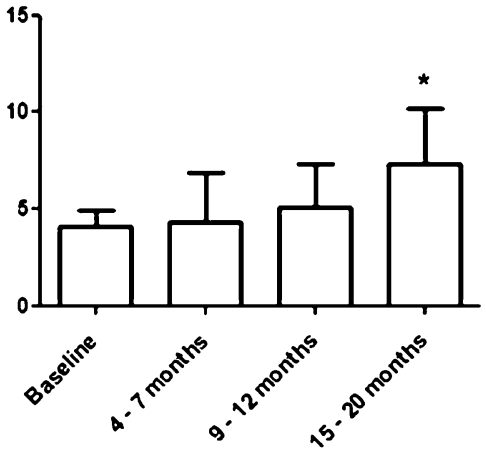

IL-10
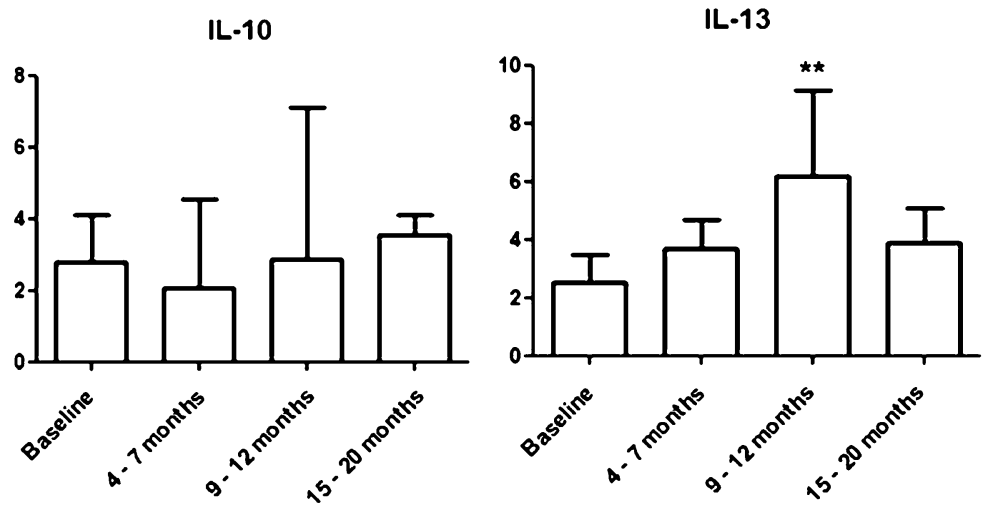

Fig. 2 Long-term effects of natalizumab treatment in cytokine serum levels. Increased concentrations were detected for IL-1 $\beta$, IL-2, and IL-17 and also for IL-5 and IL-13. Serum levels are shown in picograms per milliliter. ${ }^{*} p<0.05,{ }^{* *} p<0.01,{ }^{* * *} p<0.001$ 


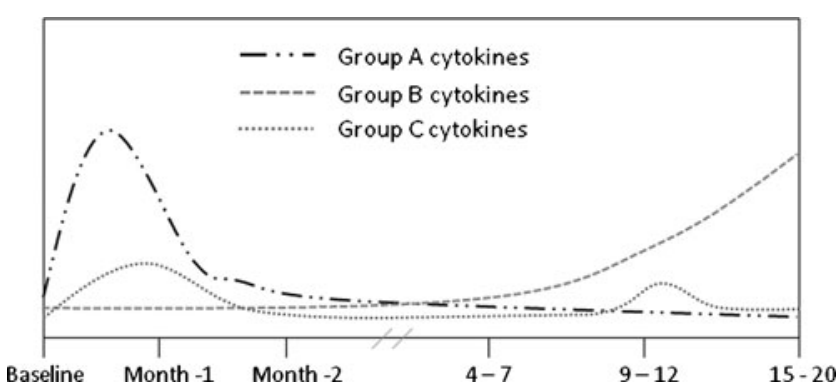

Fig. 3 Longitudinal pattern of cytokine serum levels after treatment with natalizumab. Three different patterns were observed after initiating treatment with natalizumab in the patient cohort. Some of the cytokines (Group A), including IL-4, IL-10, and IFN- $\gamma$, were elevated only during the first month. In contrast, another group of proinflammatory cytokines (Group B, including IL-1 $\beta$, IL-2 and IL-17) were elevated only at the long-term. The third group (Group $C$ ), composed of the anti-inflammatory cytokines IL-5 and IL13, was elevated only within the first month and at the end but normal in the mid-term

implicated in Th17 cell induction, would also be increased with natalizumab. Another recent paper has reported increased levels of $\mathrm{CD}^{+} \mathrm{T}$ cells producing proinflammatory IFN- $\gamma$, tumor necrosis factor (TNF), and interleukin (IL)-17 upon stimulation in vitro with anti-CD3 in blood samples from patients after 6 months treatment with natalizumab [20]. Those authors have also found that the $\mathrm{CD}^{+}$markers CD25, HLA-DR, and CCR6, as well as the frequency of $\mathrm{CD} 8^{+} \mathrm{T}$ cells producing IL-2 and IL-17, were increased. In agreement with some of these observations, our results also suggest elevated IL-17 levels at the long-term treatment with natalizumab. Although our observations require replication with larger numbers of patients for confirmation, Natalizumab treatment did induce some

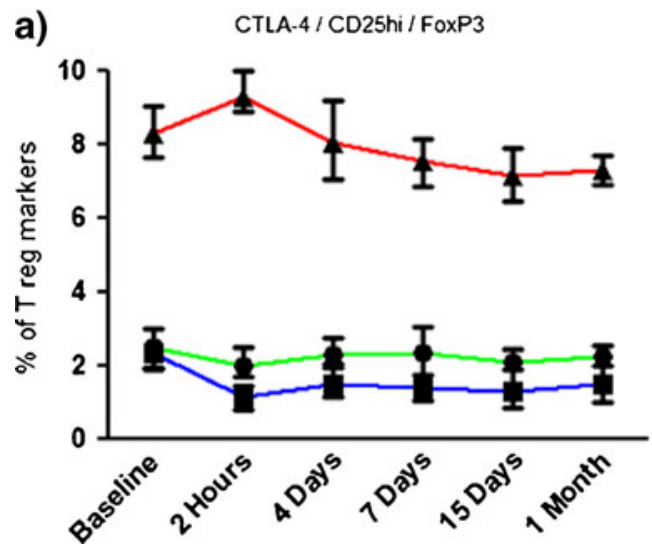

Fig. 4 Effects of natalizumab treatment on regulatory $\mathrm{T}$ cells. Regulatory $\mathrm{T}$ cell frequency (a) is shown by following the regulatory $\mathrm{T}$ cell markers CD25hi, Foxp3+, and CTLA4. None of the markers changed significantly, although there was a non-significant relative decrease in the first month. HLA-DR and CD38 activation markers were also not affected by treatment (data not shown). In vitro modifications in cytokine patterns in our cohort of RRMS patients. Furthermore, these responses seemed to be different at several stages; there was a rapid rise in cytokines after the first administration when rejection and allergic reaction might occur, whereas other cytokines were only elevated at the long-term treatment when the risk of opportunistic infections or PML risk is higher.

Natalizumab was not designed to have biological effects upon binding to $\alpha 4$ but rather to physically interfere with the endothelial attachment of VLA- $4^{+}$cells [1]. However, previous studies in rats suggested that antibody binding to VLA-4 might mediate VLA-4 ${ }^{+}$cell stimulation $[21,22]$. As we observed different cytokine response patterns in patients, we decided to test whether natalizumab exposure might affect mononuclear cells in vitro. Previous groups have addressed this question for CD4+ T cells [17]. Since the VLA-4 antigen is present in many blood cell subtypes, we co-cultured total purified PBMCs in the presence of physiological concentrations of natalizumab. We did not detect significant effects on proliferation, and we did not observe differences in cytokine patterns when the antibody was present. Therefore, if natalizumab does have any effect on blood cells, these effects might be more than just on proliferation or cytokine production and should be further addressed. It would be important to mention that this effect (if it exists) might depend on the subject or patient studied (note that we only used healthy donors because of the heterogeneity of RRMS patients).

In accordance with recent studies, we found that natalizumab does not affect regulatory $\mathrm{T}$ cell function. A recent study showed that the capacity to migrate across the blood brain barrier and suppressive function as well as foxp $3+$ cell frequency seem to not be affected by natalizumab [18]. At

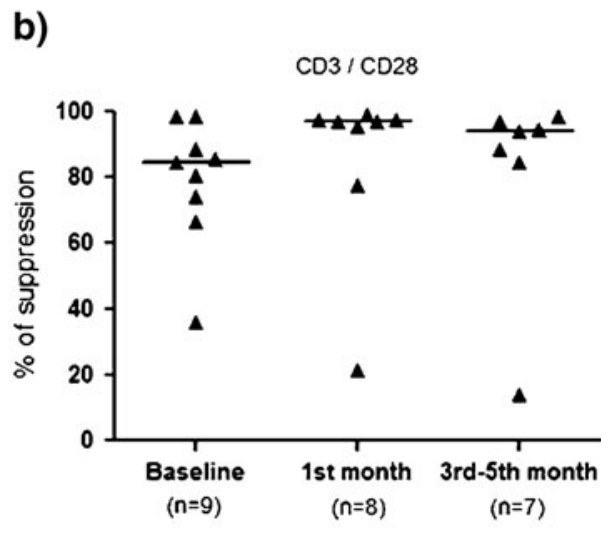

suppressor function of regulatory $\mathrm{T}$ cells is also shown (b). Peripheral mononuclear cells were stimulated with anti-CD28 plus anti-CD3 in the presence (or not) of purified regulatory $\mathrm{T}$ cells in order to obtain percentages of proliferation under different conditions. Proliferation levels of unstimulated cells were considered the control level for suppression $(100 \%)$ 
this time, there are contradictory results on the effect of natalizumab on the frequency of circulating regulatory $\mathrm{T}$ cells and another group has reported a relative decrease in CD4 + CD25 $5^{\text {high }}$ cells [23]. However, none of these studies have found any effect on the suppressor function of the cells $[18,23]$. In our case, we detected a relative tendency to a decrease in the frequency of CD4+ CD25 FoxP3+ cells within the first month (not significant); however, we also did not obtain any difference in the suppressor function of these cells in comparison with baseline levels. It would also be interesting to consider other regulatory $\mathrm{T}$ cell markers in our study like the ILR-7 receptor (CD127) or the CD39 ectonucleotidase [24], but, unfortunately, this was not considered at the beginning of our study. Already existing drugs for MS like interferon-beta and glatiramer acetate seem to modify $\mathrm{CD}^{+} \mathrm{CD} 25^{+}$Foxp3 regulatory $\mathrm{T}$ cell activity [710]. Regulatory $\mathrm{T}$ cells have been described as important players in controlling immune response and balancing tolerance versus autoimmune responses $[25,26]$. Our results, in accordance with some of the previous reports suggest that natalizumab seems to exert its beneficial properties independently of affecting regulatory $\mathrm{T}$ cell function.

In summary, treatment with natalizumab in RRMS patients induces changes in the inflammatory mechanism. While IFN- $\gamma$, IL-12p70, IL-4, and IL-10 were elevated just a few hours or days after first IV infusion, proinflammatory cytokines like IL-1 $\beta$, IL-2, and IL-17 were elevated only at the long-term treatment suggesting different immune mechanisms. We have found that globally the treatment with the antibody does not modify regulatory $\mathrm{T}$ cell function. All these results suggest other immunological effects of natalizumab in addition to VLA-4 interaction and CNS extravasation inhibition. If these changes in the cytokine equilibrium are related to beneficial or negative side effects associated to natalizumab is as yet unknown and requires further investigation.

Acknowledgments This work was supported by a grant from Biogen Idec. We thank the Neurology Department and Neuroscience Research Laboratory staff at La Paz University Hospital and La Paz Research Institute (Idipaz). We also want to thank all the MS patients and healthy donors who voluntarily and generously participated in the study.

Conflict of Interest Statement E. Diez-Tejedor has collaborated as clinical advisor investigator in clinical trials as speaker with the following companies: Astra-Zeneca, Bayer, Bristol-Myers Squibb, Boehringer Ingelheim, Cellerix, Ferrer Grupo, Knoll, Lilly, ParkeDavis, Pfizer, Sanofi-Synthelabo, Servier, UCB Pharma, Uriach, and EVER Neuro Pharma. C. Oreja-Guevara has collaborated as consultant and in clinical trials with Biogen Idec, Merck Serono, Teva, Bayer-Schering, and Novartis.

Open Access This article is distributed under the terms of the Creative Commons Attribution Noncommercial License which permits any noncommercial use, distribution, and reproduction in any medium, provided the original author(s) and source are credited.

\section{References}

1. Ransohoff RM. Natalizumab for multiple sclerosis. N Engl J Med. 2007;356(25):2622-9.

2. Gold R et al. Expert opinion: guidelines for the use of natalizumab in multiple sclerosis patients previously treated with immunomodulating therapies. J Neuroimmunol. 2007;187 (1-2):156-8.

3. Goodin DS et al. Assessment: the use of natalizumab (Tysabri) for the treatment of multiple sclerosis (an evidence-based review): report of the Therapeutics and Technology Assessment Subcommittee of the American Academy of Neurology. Neurology. 2008;71(10):766-73.

4. Baron JL et al. Surface expression of alpha 4 integrin by CD4 T cells is required for their entry into brain parenchyma. J Exp Med. 1993;177(1):57-68.

5. Yednock TA et al. Prevention of experimental autoimmune encephalomyelitis by antibodies against alpha 4 beta 1 integrin. Nature. 1992;356(6364):63-6.

6. Hellwig $\mathrm{K}$ et al. Allergic and nonallergic delayed infusion reactions during natalizumab therapy. Arch Neurol. 2008;65 (5):656-8.

7. Saresella M et al. CD4+CD25+FoxP3 $+\mathrm{PD} 1$ - regulatory T cells in acute and stable relapsing-remitting multiple sclerosis and their modulation by therapy. FASEB J. 2008;22(10):3500-8.

8. Vandenbark AA et al. Interferon-beta-1a treatment increases CD56bright natural killer cells and CD4+CD25+ Foxp3 expression in subjects with multiple sclerosis. J Neuroimmunol. 2009;215(1-2):125-8.

9. Martin-Saavedra FM et al. Beta interferon restricts the inflammatory potential of CD4+ cells through the boost of the Th2 phenotype, the inhibition of Th17 response and the prevalence of naturally occurring $\mathrm{T}$ regulatory cells. Mol Immunol. 2008;45 (15):4008-19.

10. Namdar A et al. Effect of IFN-beta therapy on the frequency and function of $\mathrm{CD} 4(+) \mathrm{CD} 25(+)$ regulatory $\mathrm{T}$ cells and Foxp3 gene expression in relapsing-remitting multiple sclerosis (RRMS): a preliminary study. J Neuroimmunol. 2010;218(12):120-4.

11. Sellner $\mathrm{J}$ et al. Effect of interferon-beta and atorvastatin on Th1/ Th2 cytokines in multiple sclerosis. Neurochem Int. 2008;53(12): $17-21$.

12. Krakauer $M$ et al. Increased IL-10 mRNA and IL-23 mRNA expression in multiple sclerosis: interferon-beta treatment increases IL-10 mRNA expression while reducing IL-23 mRNA expression. Mult Scler. 2008;14(5):622-30.

13. Sega $\mathrm{S}$ et al. IFN-beta1a and IFN-betalb have different patterns of influence on cytokines. Clin Neurol Neurosurg. 2004;106(3):255-8.

14. Schrempf W, Ziemssen T. Glatiramer acetate: mechanisms of action in multiple sclerosis. Autoimmun Rev. 2007;6(7):469-75.

15. Polman $\mathrm{CH}$ et al. Diagnostic criteria for multiple sclerosis: 2005 revisions to the "McDonald Criteria". Ann Neurol. 2005;58 (6):840-6.

16. de Andres $\mathrm{C}$ et al. Interferon beta-1a therapy enhances CD4+ regulatory T-cell function: an ex vivo and in vitro longitudinal study in relapsing-remitting multiple sclerosis. J Neuroimmunol. 2007;182(1-2):204-11.

17. Kivisakk $P$ et al. Natalizumab treatment is associated with peripheral sequestration of proinflammatory $\mathrm{T}$ cells. Neurology. 2009;72(22):1922-30.

18. Stenner MP et al. Effects of natalizumab treatment on Foxp3+ T regulatory cells. PLoS ONE. 2008;3(10):e3319.

19. Mellergard $J$ et al. Natalizumab treatment in multiple sclerosis: marked decline of chemokines and cytokines in cerebrospinal fluid. Mult Scler. 2010;16(2):208-17. 
20. Khademi $M$ et al. Induction of systemic TNFalpha in natalizumab-treated multiple sclerosis. Eur J Neurol. 2008;15 (3):309-12.

21. Dackiw AP et al. Integrin engagement induces monocyte procoagulant activity and tumor necrosis factor production via induction of tyrosine phosphorylation. J Surg Res. 1996;64 (2):210-5

22. Yurochko $\mathrm{AD}$ et al. Integrins as a primary signal transduction molecule regulating monocyte immediate-early gene induction. Proc Natl Acad Sci USA. 1992;89(19):9034-8.
23. Putzki $\mathrm{N}$ et al. Effects of natalizumab on circulating $\mathrm{B}$ cells. $\mathrm{T}$ regulatory cells and natural killer cells. Eur Neurol. 2010;63 (5):311-7.

24. Fletcher JM et al. CD39+Foxp3+ regulatory T Cells suppress pathogenic Th17 cells and are impaired in multiple sclerosis. J Immunol. 2009;183(11):7602-10.

25. Baecher-Allan C, Hafler DA. Suppressor T cells in human diseases. J Exp Med. 2004;200(3):273-6.

26. Valencia X, Lipsky PE. CD4+CD25+FoxP3+ regulatory T cells in autoimmune diseases. Nat Clin Pract Rheumatol. 2007;3(11):619-26. 